\title{
Numerical Simulation of Supersonic Carman Curve Bodies with Aerospike
}

\author{
HaiLong Zhao, Ke Peng $(\mathbb{D}$, ZePing Wu $(\mathbb{D}$, WeiHua Zhang, JiaWei Yang, and JingBo Sun \\ College of Aerospace Science and Engineering, National University of Defense Technology, Changsha 410073, China \\ Correspondence should be addressed to Ke Peng; pengke.nudt@nudt.edu.cn
}

Received 20 July 2020; Revised 6 April 2021; Accepted 16 April 2021; Published 28 April 2021

Academic Editor: Jing-Lei Xu

Copyright ( 2021 HaiLong Zhao et al. This is an open access article distributed under the Creative Commons Attribution License, which permits unrestricted use, distribution, and reproduction in any medium, provided the original work is properly cited.

\begin{abstract}
Drag reduction is one of the important problems for the supersonic vehicles. As one of the drag reduction methods, aerospike has been used in some equipment because of its good drag reduction effect. In this paper, the numerical simulations of Carman curve bodies with different lengths of the aerospike and different radius of the flat cylindrical aerodisk in supersonic flow freestream are investigated. Based on the numerical simulations, the mechanism of drag reduction of the aerospike is discussed. The drag reduction effect influence of the parameters of the aerodisk radius and the aerospike length on the Carman curve body is analyzed. The aerodisk radius within a certain range is helpful for the drag reduction. The change of length of the aerospike has little effect on the drag of Carmen curve bodies. The drag reduction effect of the same aerospike becomes worse with the increase of the incoming Mach number.
\end{abstract}

\section{Introduction}

With the continuous development of the aerospace field, except in the civil aviation field due to economic requirements and other related restrictions, the current flight speed of most aircraft is above the supersonic speed. When the aircraft is flying at supersonic speed, the air is strongly compressed, generating shock waves, which bring a series of problems to the aircraft, such as shock wave drag and aerodynamic heating. Drag reduction and thermal protection have become one of the significant research issues of supersonic and hypersonic vehicles.

At present, the technologies about the shock wave drag reduction and thermal protection of aircraft can be divided into two categories: passive control and active control according to whether there exist energy consumption during control and the control loop mode [1], including the aerospike, energy deposition, forward-facing cavity, opposing jet, and other drag reduction and thermal protection schemes and their combinational concepts. The articles by Ahmed, Qin [2], and Sun et al. [3] summarize the current research progress of the supersonic and hypersonic drag reduction and thermal protection methods. Among these techniques, attaching an aerospike at the top of the supersonic vehicle proved to be an efficient and simple way to accomplish a significant reduction in drag and aerodynamic heating [4]. And the aerospikes are the sole drag and aeroheating device that has been successfully implemented in real systems (see Figure 1), and other devices were not used in any real system [5].

The studies related to the spiked bodies' aerodynamics can be traced back to 1947. After that, aerospikes have been extensively studied over the years. And a survey about the aerospike in different sizes at the different vehicle basic configurations is presented. The survey can be divided into two parts, which are experimental studies and numerical simulations. On the one hand, the experimental studies were carried out firstly. In the Langley Pilotless Aircraft Research Division, a number of firing tests were executed on blunt and sharp nosed bodies in Mach numbers 0.95-1.37 [6]. Moeckel measured the surface pressure on a spiked parabolic forebody with a hemispherical nose in a Reynolds $2 \times 10^{5}$, Mach 1.76 and 1.93 [7].Mair experimentally examined the flow around spiked flat cylindrical and hemisphere cylindrical models in Mach 1.96 and Reynolds $2 \times 10^{5}$, and its length 


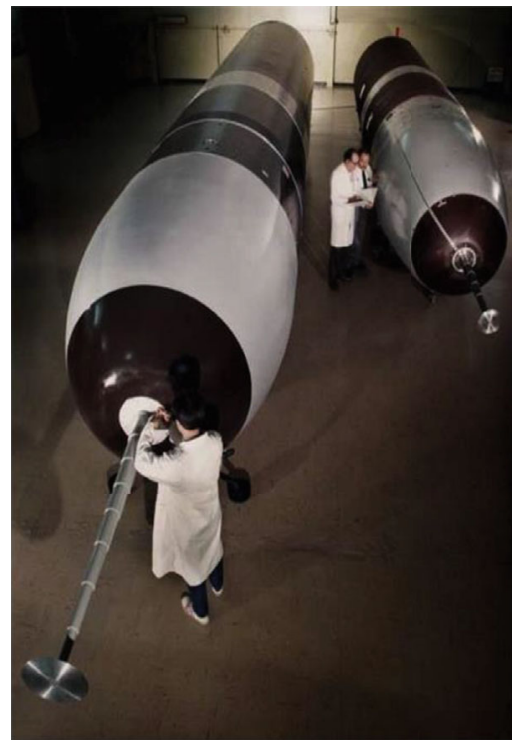

(a)

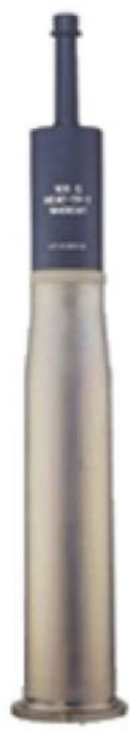

(b)

Figure 1: Some equipment with aerospike. (a) trident-II (left) and trident-I (right). (b) M490A1shell.
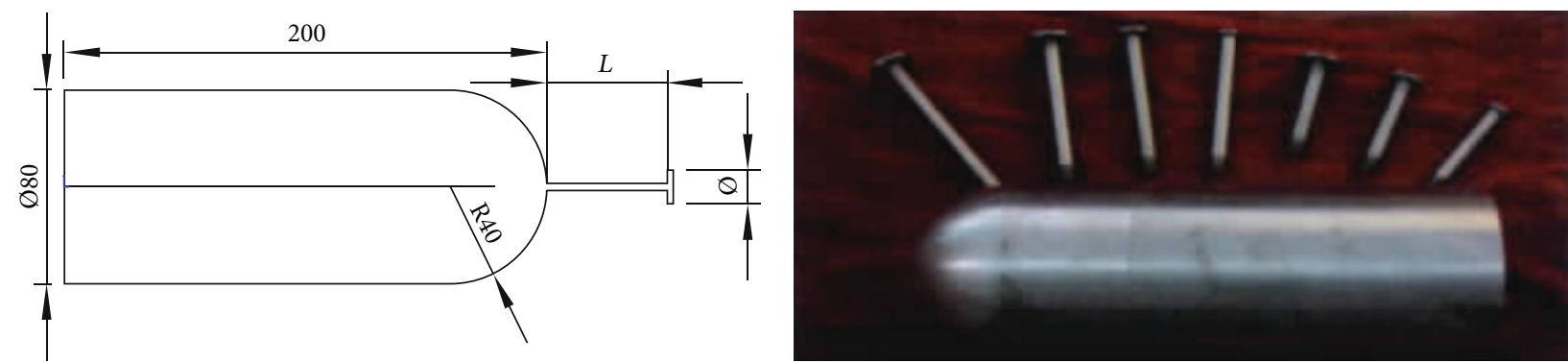

FIgUre 2: Photo of the basic model and tip spikes (unit: millimeter) [32].

TABLE 1: Flow conditions of experiment.

\begin{tabular}{lccc}
\hline$M_{\infty}$ & $P_{0}(\mathrm{kPa})$ & $T_{0}(\mathrm{~K})$ & $\operatorname{Re}(1 / \mathrm{m})$ \\
\hline 4.937 & 1000 & 373 & $2.2 \times 10^{7}$ \\
\hline
\end{tabular}

to model diameter ratio was varied up to 6 [8]. Jones investigated the flow around conical models with a hemispherical nose at a Mach of 2.72 [9]. Beastall and Turner conducted an investigation on flat cylindrical models in a Reynolds $1.125 \times 10^{6}$, Mach 1.5, 1.6, and 1.8 flow [10]. Bogdonoff and Vas undertook an experimental investigation of two models and flat cylindrical and hemisphere cylindrical models and were tested in a Mach 14, Reynolds $3.6 \times 10^{5}$ helium flow [11]. Crawford conducted an extensive experimental investigation of drag and aerodynamic heating on a spiked hemisphere cylindrical model in Mach 6.8 flow [12]. Wood was the first to investigate the variation in the flowfield structure by changing both the model geometry and the spike length in Mach 10 and Reynolds $0.5 \times 10^{5}$, which model was a cone cylindrical model [13].Holden [14] and Khlebnikov [15] focused on the heat transfer to aerospike, and the spiked models were hemisphere cylinder, flat cylinder, and conical and pyramidal aerodisks, respectively. Motoyama undertook rich experimental investigation about the pressure and heat flux distributions along a spiked hemisphere cylindrical model in a Mach 7, Reynolds $4 \times 10^{5}$ flow [16]. Milicev and Pavlovic examinded a hemisphere cylindrical model in a Mach 1.89, Reynolds $3.8 \times 10^{5}$ flow at incidence (from $-4^{\circ}$ to $10^{\circ}$ ) [17]. It is noted that all experimental investigations mainly studied the pressure and heat of basic vehicles' configuration with several aerospike and aerodisk configuration in different Mach and Reynolds numbers. On the other hand, the numerical simulation started in 1980s. Myshenkov solved the model which was a flat cylinder equipped with a point spike with a variable length [18]. Paskonov and Cheraneva solved the flowfield around cone cylindrical (semivertex angles of $70^{\circ}$ ) and flat cylindrical models equipped with pointed spikes of variable length [19]. Karlovskii and Sakharov solved the model which has a truncated conical design, whereas the spike had a hemispherical tip and a variable length. Shoemaker solved the flowfield on blunt bodies with aerospikes that are blunt cone cylindrical and hemisphere cylindrical, respectively [20]. And by the 1990s, most researches [21-24] were about the turbulence models implemented in the numerical simulation of the aerospike. The 

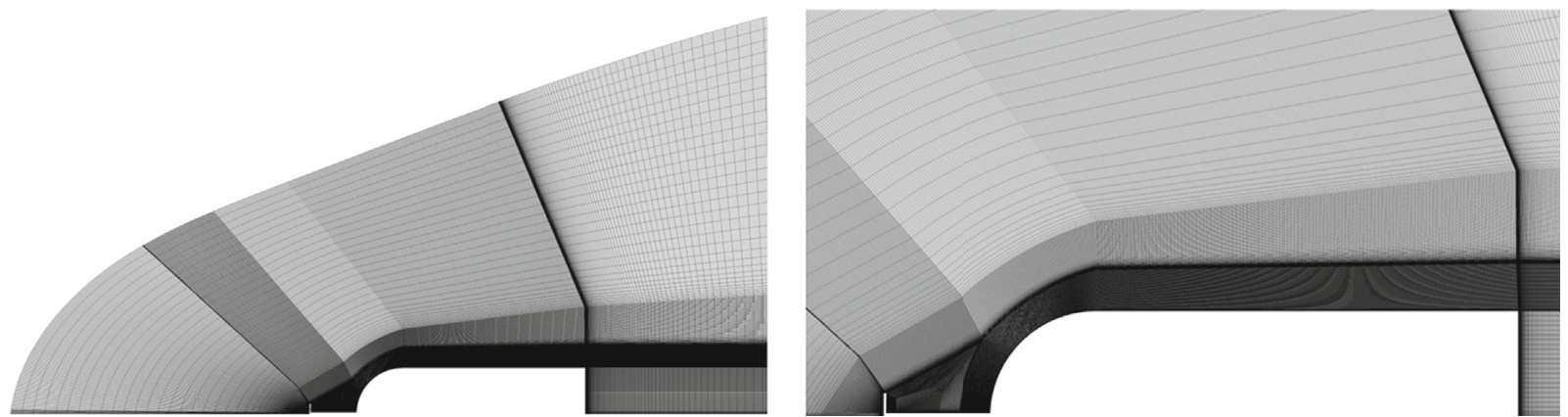

(a)
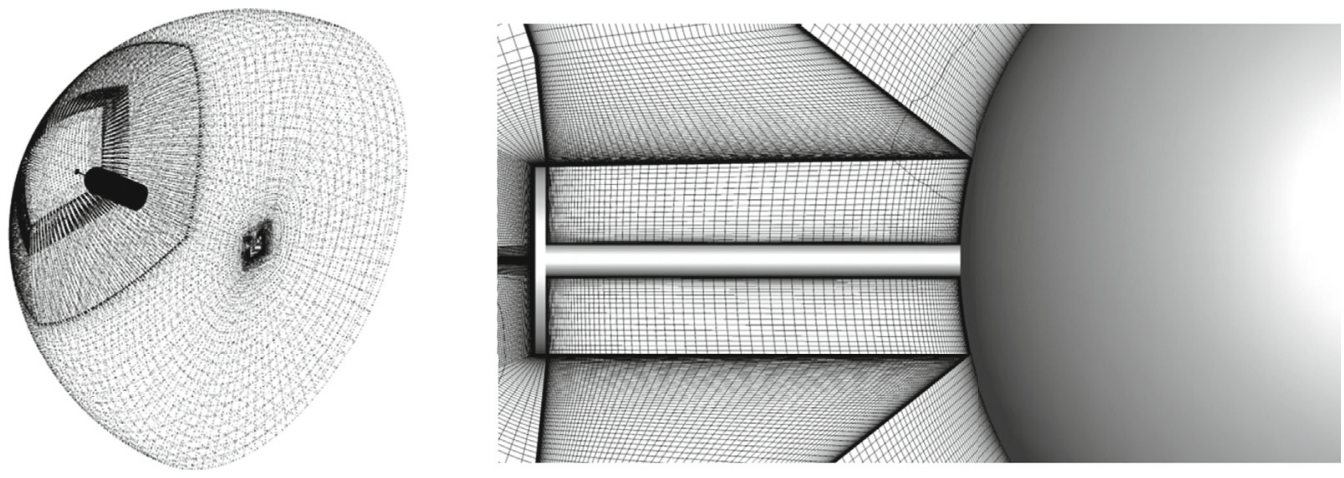

(b)

Figure 3: Computational mesh for the two cases. (a) two-dimensional and (b) three-dimensional.

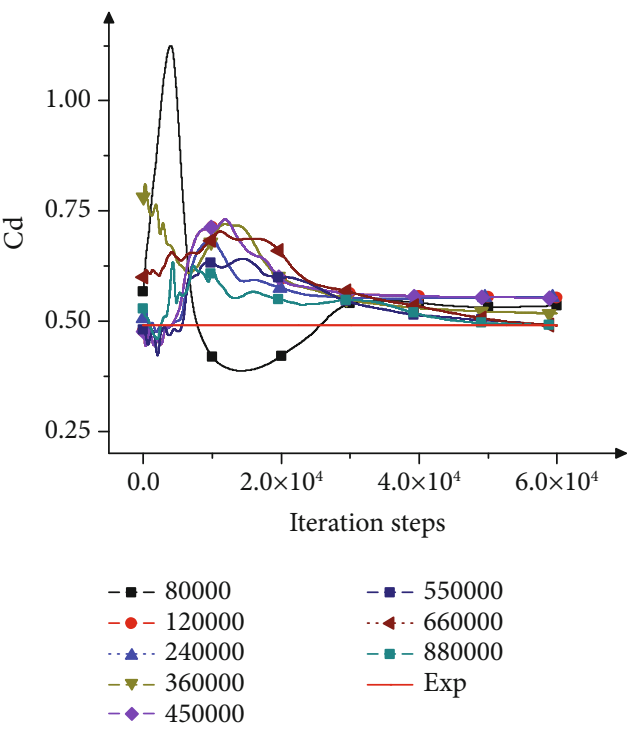

(a)

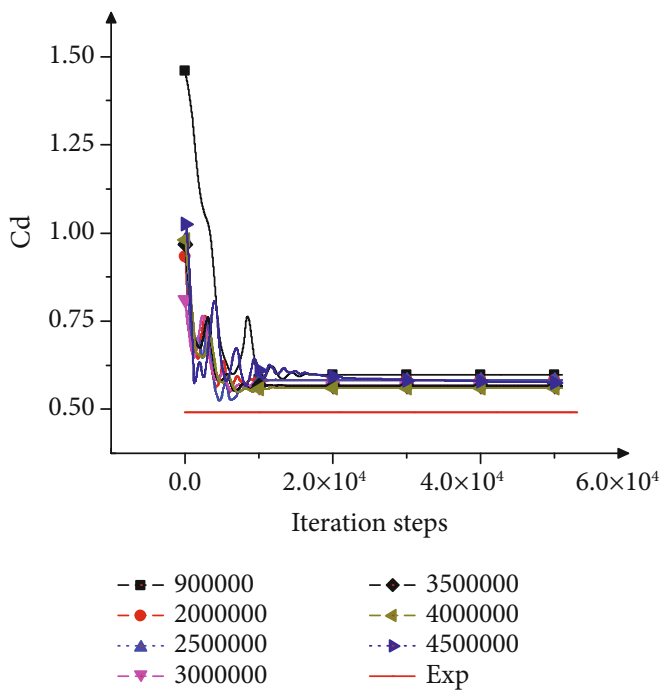

(b)

FIGURE 4: Numerical simulation results for two cases with different numbers of mesh and experimental data. (a) two-dimensional and (b) three-dimensional.

numerical simulations always used to support the experimental research, and the experimental data also used to validate the numerical simulation results. Yamauchi solved a spiked hemisphere cylindrical model in Mach 2.01, 4.15, and 6.8, Reynolds $1.4 \times 10^{5}$ flow and validated the numerical results by Crawford experiment data [25]. Mehta solved the hemisphere cylindrical model equipped with a pointed spike with the unsteady NavierStokes equations [26]. Gauer and Paull used the Crawford experiment data to validate the simulation results of the model which had a blunt conical shape, and spike had a variable length ( $L / D$ varied from 1 to 4, [27]. Gnemmi and Srulijes experimentally used the spiked hemisphere cylindrical models 


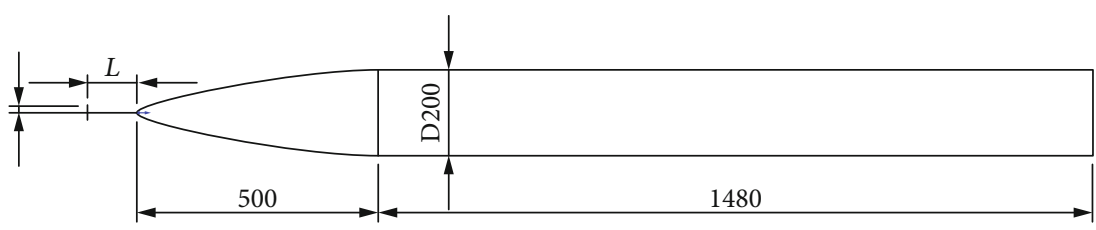

FIGURE 5: Carmen curve bodies with aerospike (unit: millimeter).

TABLE 2: Geometric dimensioning of aerospike.

\begin{tabular}{lccccc}
\hline Number & $L(\mathrm{~mm})$ & $r(\mathrm{~mm})$ & Number & $L(\mathrm{~mm})$ & $r(\mathrm{~mm})$ \\
\hline A1 & 100 & 10 & D1 & 250 & 10 \\
A2 & 100 & 15 & D2 & 250 & 15 \\
A3 & 100 & 20 & D3 & 250 & 20 \\
A4 & 100 & 25 & D4 & 250 & 25 \\
A5 & 100 & 30 & D5 & 250 & 30 \\
A6 & 100 & 35 & D6 & 250 & 35 \\
A7 & 100 & 40 & D7 & 250 & 40 \\
A8 & 100 & 45 & D8 & 250 & 45 \\
B1 & 150 & 10 & E1 & 300 & 10 \\
B2 & 150 & 15 & E2 & 300 & 15 \\
B3 & 150 & 20 & E3 & 300 & 20 \\
B4 & 150 & 25 & E4 & 300 & 25 \\
B5 & 150 & 30 & E5 & 300 & 30 \\
B6 & 150 & 35 & E6 & 300 & 35 \\
B7 & 150 & 40 & E7 & 300 & 40 \\
B8 & 150 & 45 & E8 & 300 & 45 \\
C1 & 200 & 10 & F1 & 350 & 10 \\
C2 & 200 & 15 & F2 & 350 & 15 \\
C3 & 200 & 20 & F3 & 350 & 20 \\
C4 & 200 & 25 & F4 & 350 & 25 \\
C5 & 200 & 30 & F5 & 350 & 30 \\
C6 & 200 & 35 & F6 & 350 & 35 \\
C7 & 200 & 40 & F7 & 350 & 40 \\
C8 & 200 & 45 & F8 & 350 & 45 \\
\hline
\end{tabular}

in a Mach 4.5 flow, and the model had a fixed length $(L / D=1)$ whereas flat, spherical, and biconical aerodisks and used numerical simulations are to solve these flowfield [28]. Xue solved the spike-tipped blunt nose with Mach up to 4.5 [29]. The numerical simulations of vehicles are with different sizes of aerospike and aerodisk in different Mach and Reynolds, and combined with experimental data, the models and assumptions used in the numerical simulation are validated.

The purpose of this work is contributing to the following aspects. First, the numerical simulation results of Carmen curve bodies with aerospike to discuss the mechanism of the drag reduction. Second, the Carman curve body with changes of flat cylindrical aerodisk radius $(r / d=0.05,0.1,0.125,0.15,0.175,0.2,0.225)$ and aerospike length $(L / D=0.5,0.75,1,1.25,1.5,1.75)$ is studied, and the drag reduction effect influenced by the flat cylindrical aerodisk radius and aerospike length is analyzed. Finally, Compared with the results of Carman curve body with aerospike at three Mach numbers, the drag reduction effect influenced by incoming Mach number is analyzed. Compared with other head curves, the Carman curve body is more used in missiles and rockets. So, the numerical simulation of the Carman curve body with aerospike in supersonic flow is more practical significance.

\section{Calculation Models}

2.1. Governing Equations. Fluid flow can be described by conservation of mass, momentum, and energy. The Favre Reynolds-averaged Navier-Strokes (RANS) can be written as follows [30]:

$$
\begin{gathered}
\frac{\partial \bar{\rho}_{-}}{\partial t}+\frac{\partial \rho_{-} \bar{U}_{i} \sim}{\partial t}=0 \\
\frac{\partial \bar{\rho} \widetilde{U_{i}}}{\partial t}+\frac{\partial \bar{\rho} \widetilde{U_{i}} \widetilde{U_{j}}}{\partial x_{j}}=-\frac{\partial \bar{P}}{\partial x_{i}}+\frac{\partial \overline{\sigma_{i j}}}{\partial x_{j}}-\frac{\partial \bar{\rho} \widetilde{u_{i}^{\prime} u_{j}^{\prime}}}{\partial x_{i}}, \\
\frac{\partial}{\partial t}(\bar{\rho} \tilde{E})+\frac{\partial}{\partial x_{j}}\left[\widetilde{U_{j}} \bar{\rho}\left(\tilde{E}+\frac{\bar{P}}{\bar{\rho}}\right)\right]=\frac{\partial}{\partial x_{j}}\left(\overline{\sigma_{i j}} \widetilde{U_{i}}+\overline{\sigma_{i j}} \overline{u_{i}^{\prime}}+\overline{u_{i}^{\prime} \sigma_{i j}^{\prime}}\right) \\
-\frac{\partial}{\partial x_{j}}\left(\overline{q_{j}} \bar{\rho} c_{p} \widetilde{u_{i}^{\prime} T^{\prime \prime}}+\bar{\rho} \tau_{i j} \widetilde{U_{i}}+\frac{\bar{\rho} \widetilde{u}_{i}^{\prime} u_{i}^{\prime} u_{j}^{\prime}}{2}\right) .
\end{gathered}
$$

In equations (2) and (3), $\overline{\sigma_{i j}}$ is the viscous stress tensor that can be written as follows:

$$
\overline{\sigma_{i j}} \simeq 2 \bar{\mu}\left(\widetilde{S_{i j}}-\frac{1}{3} \widetilde{S_{k k}} \delta_{i j}\right) \widetilde{S_{i j}}=\frac{1}{2}\left(\frac{\partial \widetilde{U_{i}}}{\partial x_{j}}+\frac{\partial \widetilde{U_{j}}}{\partial x_{i}}\right) .
$$

In the energy conservation equation, $\overline{q_{j}}$ represented the molecular heat flux.

$$
\overline{q_{j}} \simeq-\frac{C_{p} \bar{\mu}}{\operatorname{Pr}} \frac{\partial \bar{T}}{\partial x_{j}} .
$$

In equations (5), $C_{p}$ is the specific heat at constant pressure, and $P r$ is the molecular Prandtl number. In equations (1)-(3), the physical variable, like the velocity component $U_{i}$, had decomposed into a Favre-averaging part $\widetilde{U_{i}}$, represented by the tilde, and a Favre-fluctuating part $u_{p}^{\prime}$ represented by 


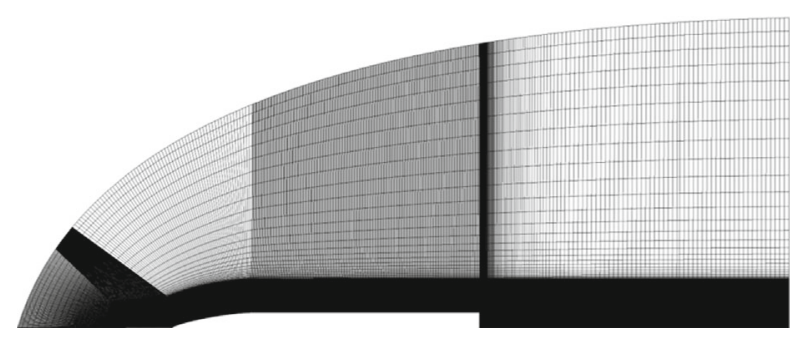

(a)

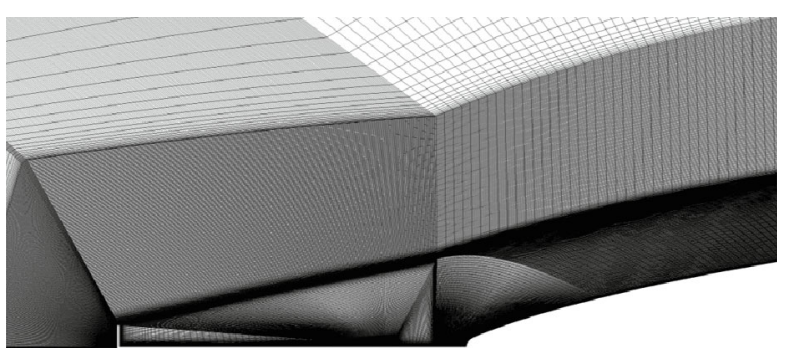

(b)

FIgure 6: The mesh of Carmen curve bodies with aerospike. (a) Global mesh. (b) Mesh of the aerospike.

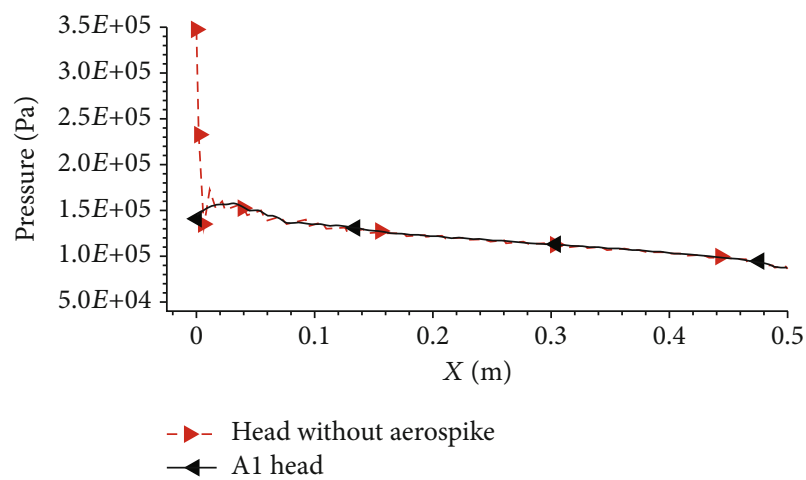

(a)

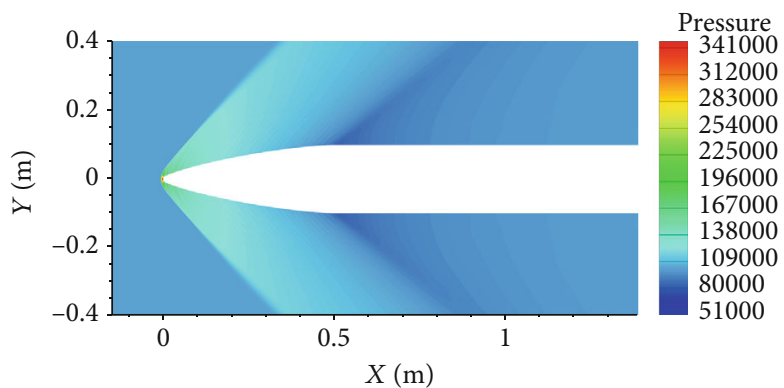

(b)

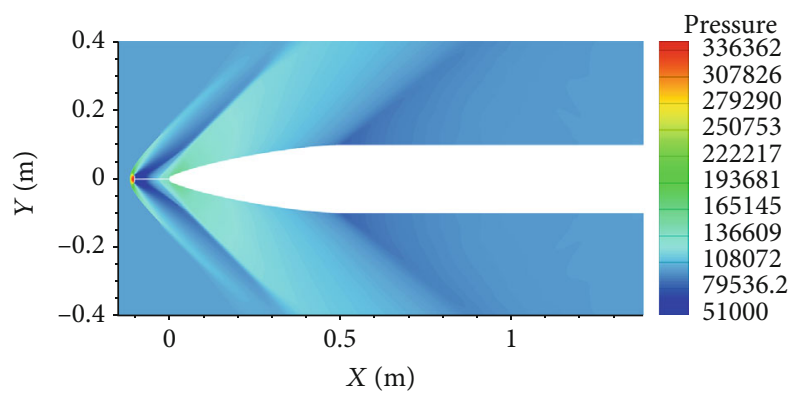

(c)

FIGURE 7: Head pressure and pressure contour for the basic model and A1. (a) Head pressure (b), pressure contour for the basic model, and (c) pressure contour for the A1.

the double prime. There are a number of unknown physical variables in equations (2) and (3), such as $\widetilde{u_{i}^{\prime} u_{p}^{\prime}} \overline{u_{i}^{\prime}}, \frac{}{u_{i}^{\prime} \sigma_{i j}^{\prime}} \widetilde{u_{i}^{\prime} u_{i}^{\prime} u_{j}^{\prime}}$ and $\widetilde{u_{i}^{\prime} T^{\prime \prime}}$, and it is necessary to use other models. In the present work, the Boussinesq hypothesis on the second-order correlations is adopted. Thus, for the Reynolds stress, the following constitutive relation holds [29]:

$$
\widetilde{u_{i}^{\prime} u_{j}^{\prime}}=-2 v_{t}\left(\widetilde{S_{i j}}-\frac{1}{3} \widetilde{S_{k k}} \delta_{i j} k\right) \text {. }
$$

In equations (6), $k=0.5 \widetilde{u_{i}^{\prime} u_{i}^{\prime}}$ represents the turbulent kinetic energy, and $v_{t}=\mu_{t} / \bar{\rho}$ is the kinetic eddy viscosity. By analogy to the Reynolds stress relation, the correlation $\widetilde{u_{i}^{\prime} T^{\prime \prime}}$ takes a similar diffusivity model.

$$
\widetilde{u_{i}^{\prime} T^{\prime \prime}}=-\frac{v_{t}}{\operatorname{Pr}_{t}} \frac{\partial \tilde{T}}{\partial x_{j}}
$$

With equations (6) and (7), the momentum and energy equations can be written as follows:

$$
\begin{gathered}
\frac{\partial \bar{\rho} \widetilde{U_{i}}}{\partial t}+\frac{\partial \bar{\rho} \widetilde{U_{i}} \widetilde{U_{j}}}{\partial x_{j}}=-\frac{\partial \bar{P}}{\partial t}+\frac{\partial}{\partial x_{j}}\left[2\left(\bar{\mu}+\mu_{t}\right)\left(\widetilde{S_{i j}}-\frac{1}{3} \widetilde{S_{k k}} \delta_{i j}\right)\right], \\
\frac{\partial}{\partial t}(\bar{\rho} \tilde{E})+\frac{\partial}{\partial x_{j}}\left[\overline{U_{j}} \bar{\rho}\left(\tilde{E}+\frac{\bar{P}}{\bar{\rho}}\right)\right]=\frac{\partial}{\partial x_{j}}\left[2 \overline{U_{i}}\left(\bar{\mu}+\mu_{t}\right)\left(\widetilde{S_{i j}}-\frac{1}{3} \widetilde{S_{k k}} \delta_{i j}\right)+C_{p}\left(\frac{\bar{\mu}}{\operatorname{Pr}}+\frac{\mu_{t}}{\operatorname{Pr}_{t}}\right) \frac{\partial \tilde{T}}{\partial x_{j}}\right] .
\end{gathered}
$$

2.2. $k-\omega$ SST Transport Model. For the aerospike numerical simulation, Roy and Blottner found that the $k-\omega$ SST transport model performs the best among a total of 18 one- and two-equation turbulence models [31]. 


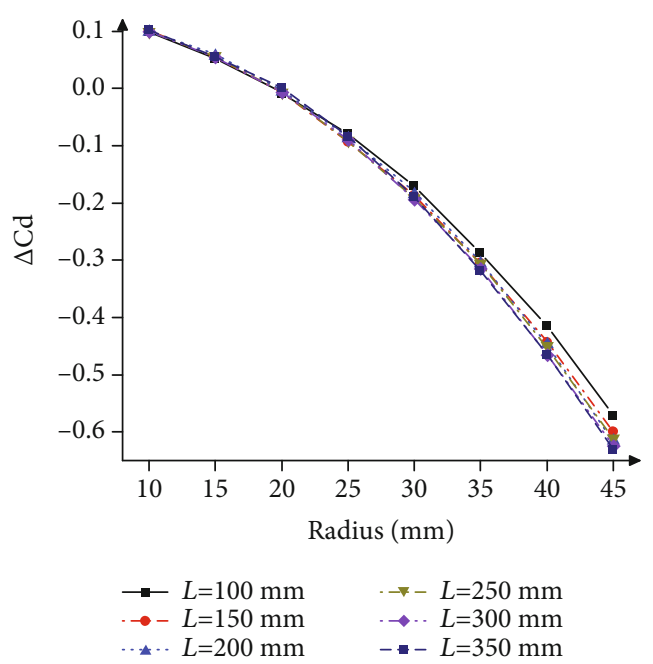

(a)

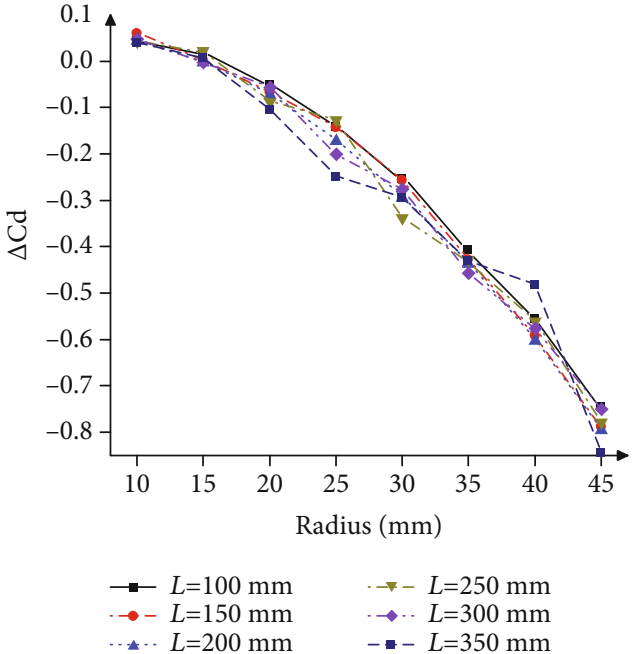

(b)

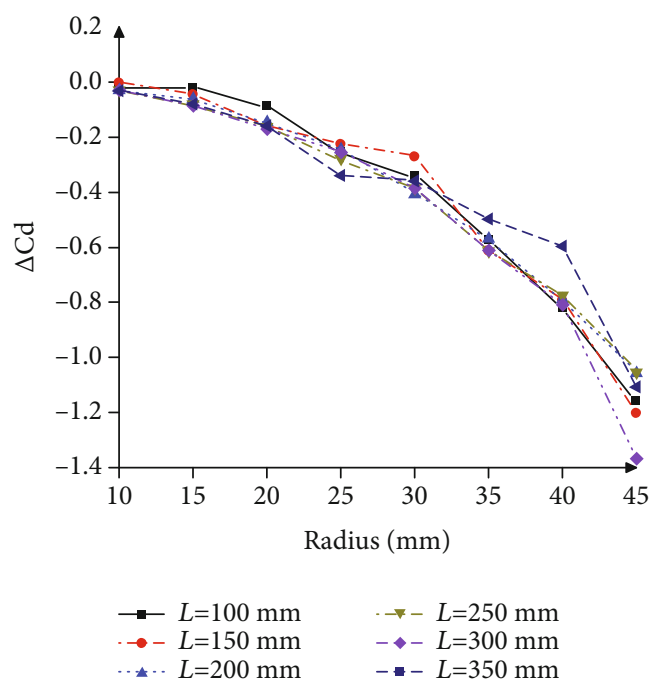

(c)

Figure 8: Drag reduction rate and radius of the aerodisk. (a) Ma 1.5, (b) Ma 2, and (c) Ma 3.

The $k-\omega$ SST transport model requires the solution of transport equations for $k$ and $\omega$ :

$$
\begin{gathered}
\frac{\partial \rho k}{\partial t}+\frac{\partial}{\partial x_{j}}\left[\rho u_{j} k-\left(\mu+\sigma_{k} \mu_{t}\right) \frac{\partial k}{\partial x_{j}}\right]=\tau_{i j} S_{i j}-\beta^{*} \rho k \omega, \\
\frac{\partial \rho \omega}{\partial t}+\frac{\partial}{\partial x_{j}}\left[\rho u_{j} \omega-\left(\mu+\sigma_{\omega} \mu_{t}\right) \frac{\partial \omega}{\partial x_{j}}\right]=P_{\omega}-\beta k \omega^{2}+2\left(1-F_{1}\right) \frac{\rho \sigma_{\omega 2}}{\omega} \frac{\partial k}{\partial x_{j}} \frac{\partial \omega}{\partial x_{j}},
\end{gathered}
$$

where $S$ is the mean strain rate, and $F_{1}$ is a blending function expressed as

$$
F_{1}=\tanh \left\{\left\{\min \left[\max \left(\frac{\sqrt{k}}{0.09 \omega d}, \frac{500 \mu}{\rho d^{2} \omega}\right), \frac{4 \rho \sigma_{\omega 2} k}{C D_{k \omega} d^{2}}\right]\right\}^{4}\right\},
$$

with

$$
C D_{k w}=\max \left(\frac{2 \rho \sigma_{\omega 2}}{\omega} \frac{\partial k}{\partial x_{j}} \frac{\partial \omega}{\partial x_{j}}, 10^{-20}\right)
$$

And the model constants depend on $F_{1}$. The eddy viscosity $\mu_{T}$ is calculated from

$$
\mu_{t}=\min \left(\frac{\rho k}{\omega}, \frac{\rho a_{1} k}{\Omega F_{2}}\right)
$$

where $a_{1}=0.31$, and $F_{2}$ is also a blending function:

$$
F_{2}=\tanh \left\{\left[\max \left(\frac{2 \sqrt{k}}{0.09 \omega d}, \frac{500 \mu}{\rho d^{2} \omega}\right)\right]^{2}\right\} .
$$




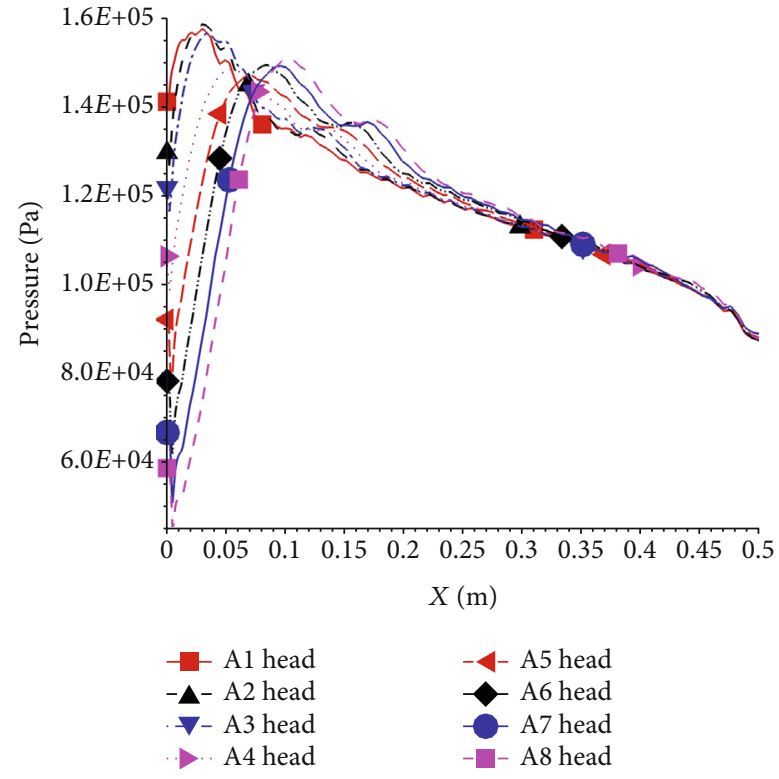

(a)

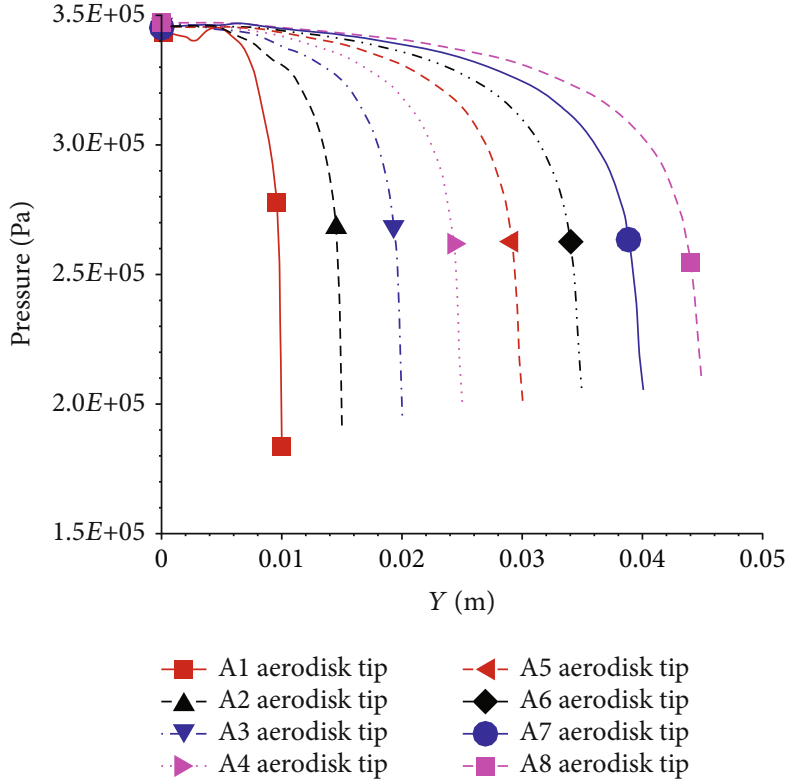

(b)

FiguRE 9: The head pressure curves and the pressure curves of the aerodisk tip at $L=100 \mathrm{~mm}$ and Mach number 1.5. (a) Head pressure curves. (b) Pressure curves of the aerodisk tip.

simulations in this paper are solved by using the fluent where implicit density-based solver is used to solve the compressible RANS. In order to reduce the mesh, the axisymmetric swirl is used. The flux is calculated by AUSM. The second order upwind is selected as the difference scheme. The $k-$ $\omega$ SST model is adopted here for turbulence quantities.

In order to check the accuracy of the above model and methods, the experimental data in reference [32] were used to compare the numerical results. Figure 2 shows the basic model and aerospike in the reference [32]. The reference [32] studied a variety of lengths of the aerospike and radius of the aerodisk. In this section, the length of the aerospike and the radius of the aerodisk are selected as $40 \mathrm{~mm}$ and $9 \mathrm{~mm}$, respectively, to carry out the numerical simulation. Table 1 shows the experimental parameters including the experimental Mach number, total pressure, and total temperature in the reference [32].

There are two groups of numerical simulation results, which one group of numerical results are acquired by axisymmetric swirl and one group of numerical results are obtained by solving in three dimensions model. The other model and methods are same between the two groups. Figure 3 shows the computational mesh for the two cases, in order to eliminate the influence of the number of mesh on the calculation results. In the two-dimensional condition, eight cases with mesh numbers of $8 \times 10^{4}, 1.2 \times 10^{5}, 2.4 \times 10^{5}, 3.6 \times 10^{5}, 4.5$ $\times 10^{5}, 5.5 \times 10^{5}, 6.6 \times 10^{5}$, and $8.8 \times 10^{5}$ were calculated. Eight cases of $9 \times 10^{5}, 1.5 \times 10^{6}, 2 \times 10^{6}, 2.5 \times 10^{6}, 3 \times 10^{6}$, $3.5 \times 10^{6}, 4 \times 10^{6}$, and $4.5 \times 10^{6}$ mesh numbers were calculated under three-dimensional condition. For all cases, the first layer mesh distance is set to $2 \times 10^{-5} \mathrm{~m}, y^{+} \approx 5$. The drag coefficient and the number of iterative steps are shown in Figure 4.
According to Figure 4, for the two-dimensional case, when the mesh number is greater than 450000, the error between the numerical simulation results and the experimental data is less than $8 \%$. For the three-dimensional case, when the mesh number is more than 3 million, the error between the numerical simulation and the experimental data is less than $10 \%$. Under the same model and numerical methods, the two-dimensional and three-dimensional cases have good prediction effect on the drag coefficient for the aerospike. In order to improve the computation efficiency, this paper adopts the two-dimensional model.

2.4. Geometric Shape and Computing Grid. The geometric shape of the Carmen curve bodies with aerospike is given in Figure 5. The diameter of the bodies is $200 \mathrm{~mm}$, the head length to diameter ration is 2.5 , and the bodies' length to diameter ratio is 9.9. And there are seven diameters of aerodisk radius and six groups of length of aerospike, as shown in Table 2.

The solution models adopt the methods and model mentioned above. The flow Mach numbers are, respectively, 1.5, 2 , and 3, and the atmospheric parameters are based on standard atmospheric sea level conditions. For the Carmen curve bodies with aerospike, the total number of mesh is 550000, the mesh setup is the same as in Section 2.3, and the first layer mesh distance is set to $2 \times 10^{-5} \mathrm{~m}, y^{+} \approx 5$, as shown in Figure 6 .

\section{Results and Discussion}

3.1. Mechanism of Aerospike Drag Reduction. Figure 7 shows the flowfield feature of the model A1 and the Carmen curve body without aerospike at Mach number 1.5. As can be seen from Figure $7(\mathrm{a})$, when the aerospike exists, the pressure 


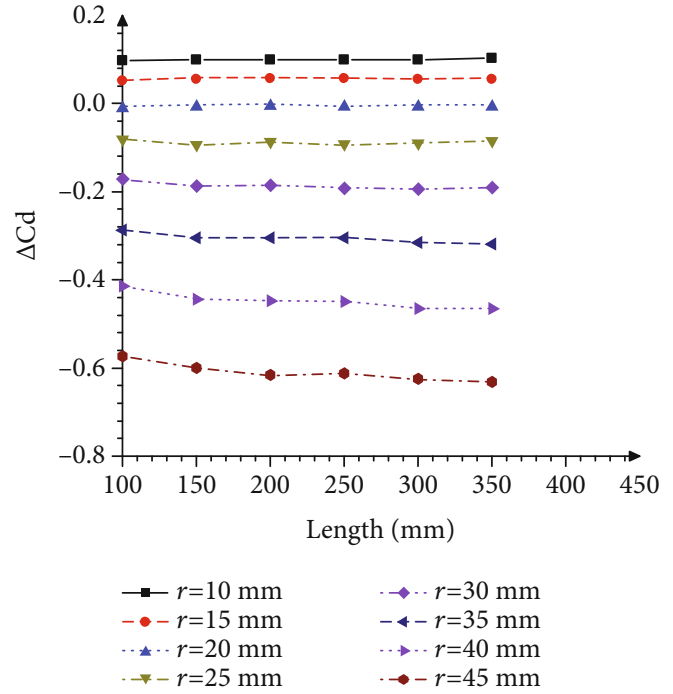

(a)

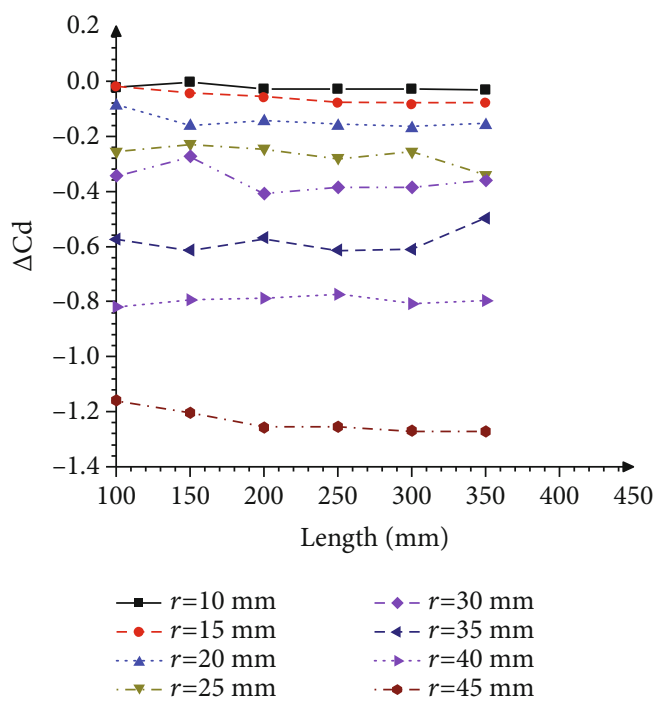

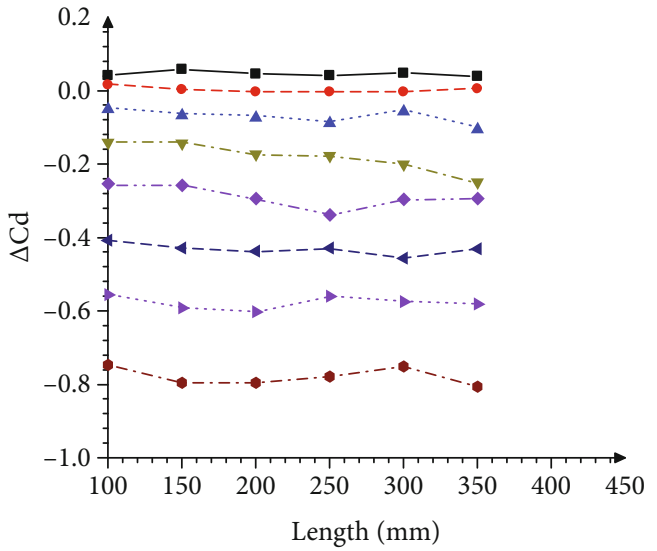

$$
\begin{array}{ll}
-r=10 \mathrm{~mm} & -\leftrightarrow r=30 \mathrm{~mm} \\
--r=15 \mathrm{~mm} & -\leftarrow-r=35 \mathrm{~mm} \\
\cdots-r=20 \mathrm{~mm} & \cdots \rightarrow r=40 \mathrm{~mm} \\
\rightarrow-r=25 \mathrm{~mm} & \rightarrow-r=45 \mathrm{~mm}
\end{array}
$$

(b)

(c)

Figure 10: Drag reduction rate and length of the aerospike. (a) Ma 1.5, (b) Ma 2, and (c) Ma 3.

curve of the head of the aircraft changes. The pressure curve of the head changes from the maximum downward decrease at the front end to a trend of first increase and then decrease. By comparing Figures 7(b) and 7(c), it can be seen that when there is an aerospike at the front of the head of the aircraft, a shock wave is generated at the front of the aerospike, and a separation area is formed between the shock wave, aerospike, and the head, which effectively reduces the pressure at the front of the head of the aircraft and thus reduces the drag of the aircraft.

In general, the drag reduction principle of aerospike is to change the flow field at the front of the aircraft, reduce the pressure on the aircraft head, and achieve the purpose of drag reduction.

3.2. Influence of Aerodisk Radius on the Drag Reduction Effect. Figure 8 shows the curve of the drag reduction rate as a function of the radius of the aerodisk at three Mach numbers.
The drag reduction rate is defined as shown in equation (14).

$$
\Delta C \mathrm{~d}=\frac{\mathrm{Cd}_{\text {basic }}-\mathrm{Cd}_{\text {aerospike }}}{\mathrm{Cd}_{\text {basic }}} .
$$

In equation (14), $\mathrm{Cd}_{\text {basic }}$ is the drag coefficient of the basic model, and $\mathrm{Cd}_{\text {aerospike }}$ is the drag coefficient of the Carmen curve bodies with aerospike.

According to Figure 8, it can be seen that the drag reduction rate decreases with the increase of the radius of aerodisk. When the Mach number is 1.5 and 2, the aerospike can produce drag reduction effect when the radius of the aerodisk is less than $15 \mathrm{~mm}$. When the radius of the aerodisk is $10 \mathrm{~mm}$, the maximum drag reduction rate can reach $11 \%$ and $7 \%$ in the calculated radius range of the aerodisk. The drag reduction effect of the aerospike on the aircraft is lost when the radius of the aerodisk exceeds $15 \mathrm{~mm}$, and the Mach number 


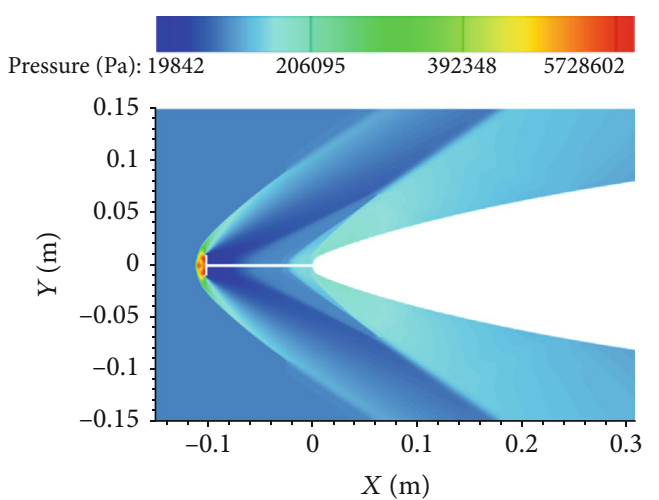

(a)

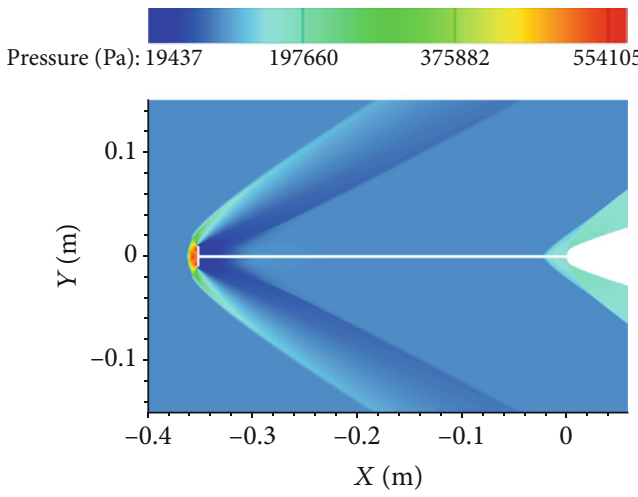

(c)

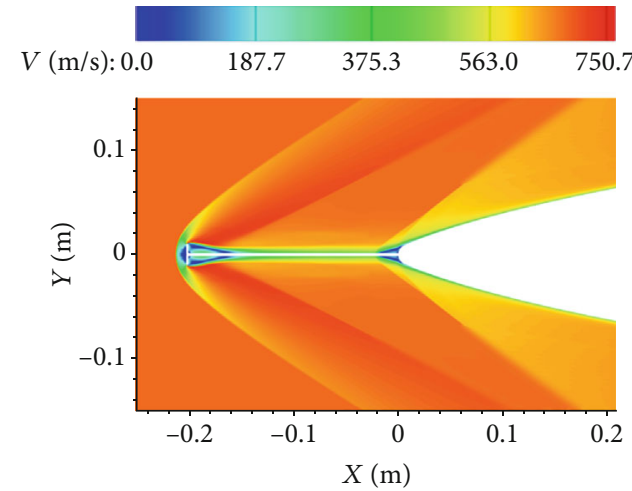

(e)

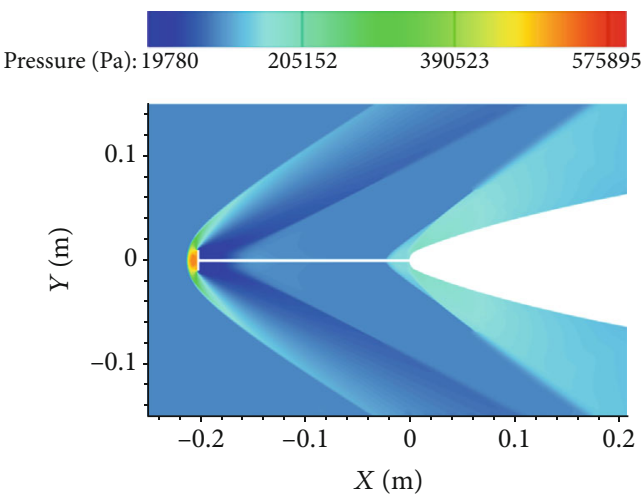

(b)

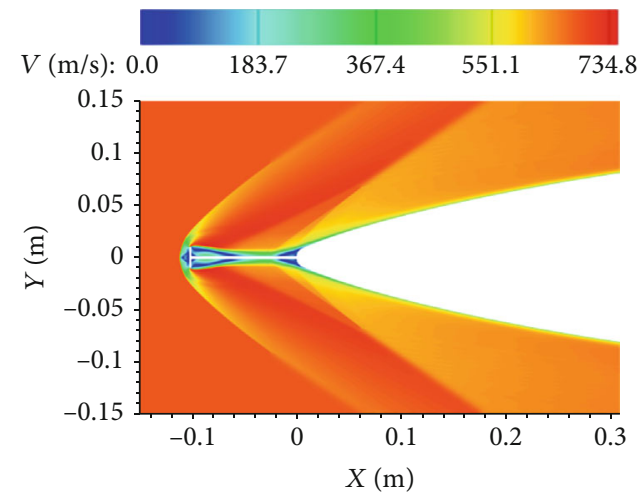

(d)
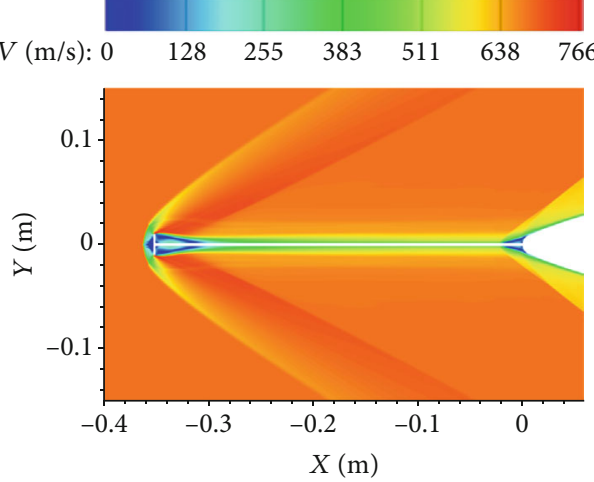

(f)

Figure 11: Continued. 


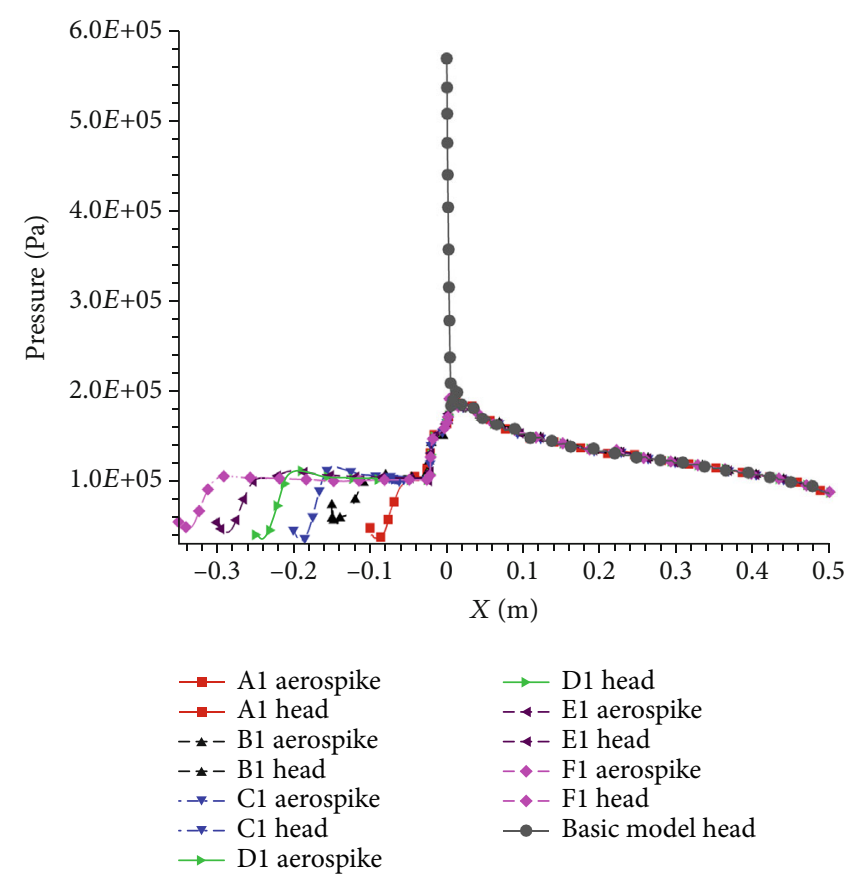

(g)

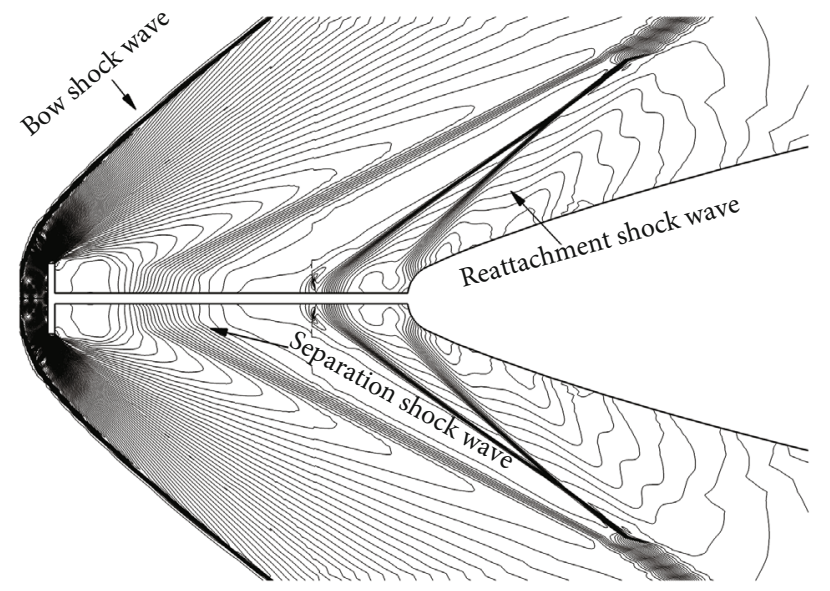

(h)

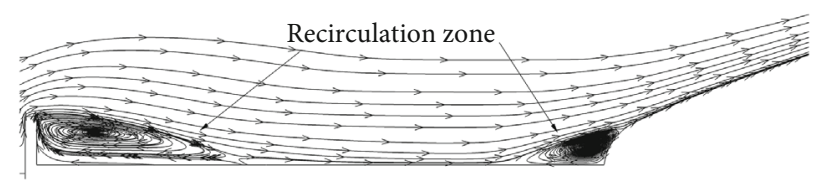

(i)

Figure 11: Flowfield features in Mach number 2. (a) $L=100 \mathrm{~mm}$ and $r=10 \mathrm{~mm}$, pressure contour. (b) $L=200 \mathrm{~mm}$ and $r=10 \mathrm{~mm}$, pressure contour. (c) $L=350 \mathrm{~mm}$ and $r=10 \mathrm{~mm}$, pressure contour. (d) $L=100 \mathrm{~mm}$ and $r=10 \mathrm{~mm}$, velocity contour. (e) $L=200 \mathrm{~mm}$ and $r=10 \mathrm{~mm}$, velocity contour. (f) $L=350 \mathrm{~mm}$ and $r=10 \mathrm{~mm}$, velocity contour. (g) $r=10 \mathrm{~mm}$, pressure curves (h). $L=100 \mathrm{~mm}$ and $r=10 \mathrm{~mm}$, pressure lines. (i) $L=100 \mathrm{~mm}$ and $r=10 \mathrm{~mm}$, streamlines.

is 1.5 and 2 , and even a negative drag reduction rate is generated which increases the drag of aircraft. When the Mach number is 3 , in the calculated radius of aerodisk, all shapes are unable to produce drag reduction effect, and all increase the drag. Though the above analysis, it can be seen that the radius of the aerodisk is an important factor affecting the drag reduction effect of the aerospike, and the same aerospike will have different drag reduction effects under different flow Mach numbers.

To futher illustrate how the radius of the aerodisk affects the drag effect, Figure 9 shows the head pressure curves and the pressure curves of the aerodisk tip at $L=100 \mathrm{~mm}$ and Mach number 1.5. As can be seen from Figure 9(a), as the radius of the aerodisk tip increases, the pressure curve of the aircraft head gradually moves downward to the right, and the peak value of the pressure curve gradually decreases. So, as the radius of aerodisk increases, the pressure on the head of the vehicle decreases, and the drag decreases. For the same inlet flow, the pressure curve of the aerodisk tip is same, but the increase of the radius of the aerodisk increases the drag generated at the aerodisk tip. Therefore, if the increased drag of the aerodisk is less than that at the head of the aircraft, the effect of drag reduction will be realized, and if the increased drag of the aerodisk is greater than that at the head of the aircraft, the aircraft drag will be increased. Therefore, when the aerospike is used to reduce the drag of the aircraft, the radius of aerodisk should be set reasonably to achieve the best drag reduction effect.

\subsection{Influence of Aerospike Length on the Drag Reduction} Effect. Figure 10 shows the curve of the drag reduction rate as a function of the aerospike length at three Mach numbers.

According to Figure 10, it shows that in the calculation of the aerospike length range, the change of aerospike length to the drag reduction effect of aerospike, the drag reduction rate, and aerospike length curve is close to a straight line, in order to further illustrate the effect of aerospike length, Figure 11 shows the flowfield features that the aerospike length is 100,200 , and $350 \mathrm{~mm}$, and the radius of aerodisk is $10 \mathrm{~mm}$ at Mach number 2 .

According to Figures 11(a)-11(f), for Carmen curve bodies, the length of aerospike changes for the flowfield feature is not big, and combined with the Figure 11(g) pressure curves, the length of aerospike did not affect pressure curves, just because of the different length, and the pressure change is different, but the pressure change trend are exactly the same. By Figures 11(h) and 11(i), the features of flowfield of the vehicles with an aerospike and a flat cylindrical aerodisk are clear. 


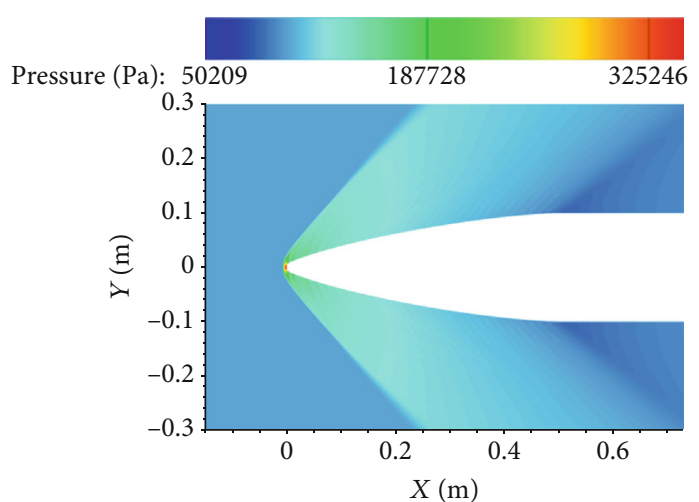

(a)

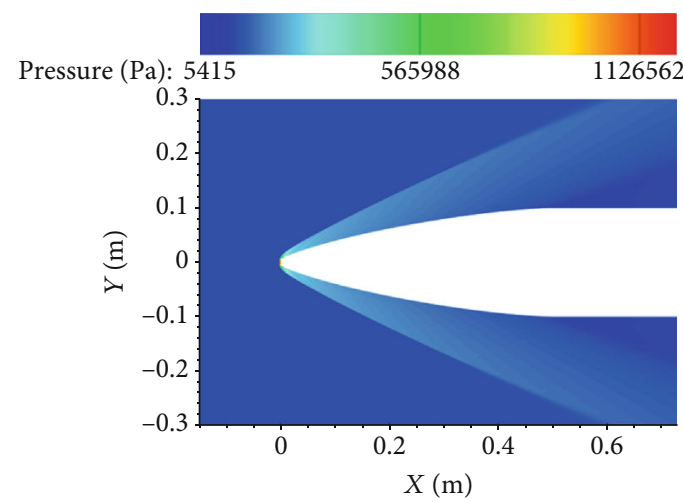

(c)

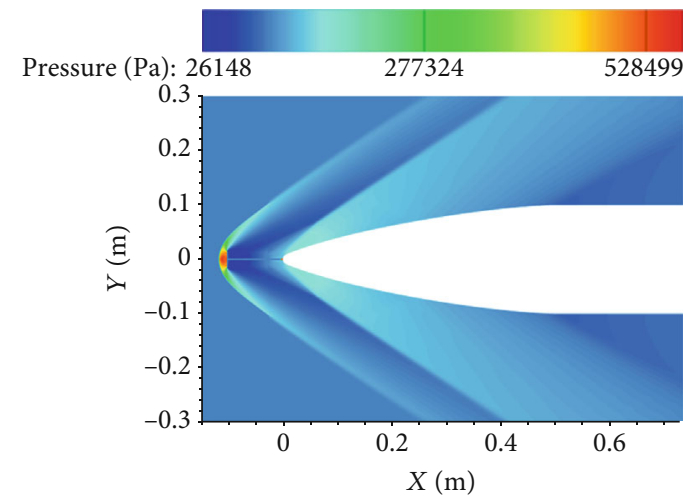

(e)

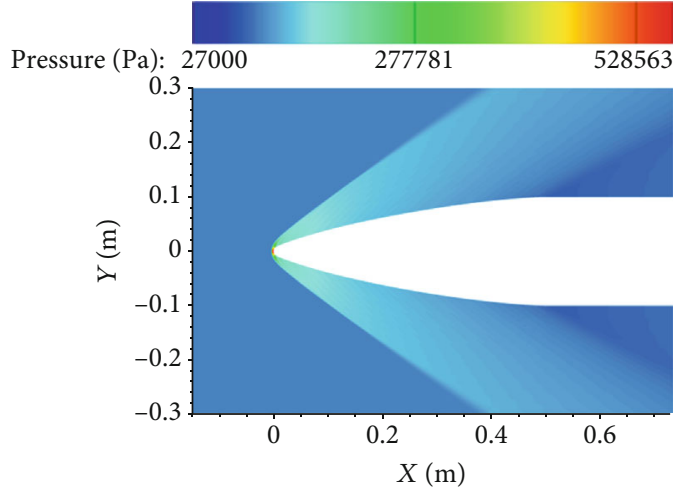

(b)

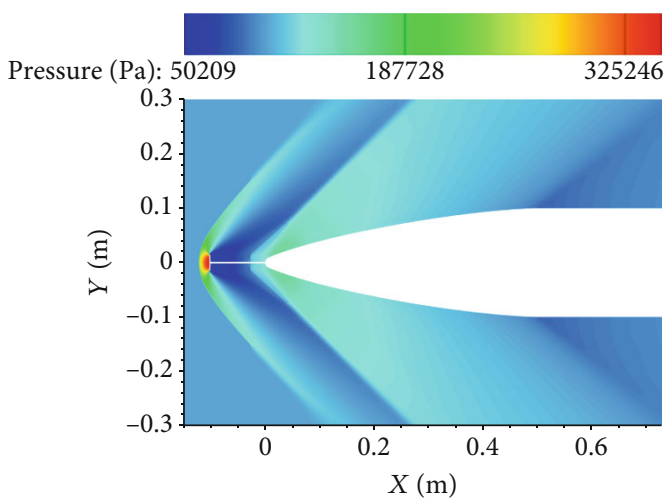

(d)

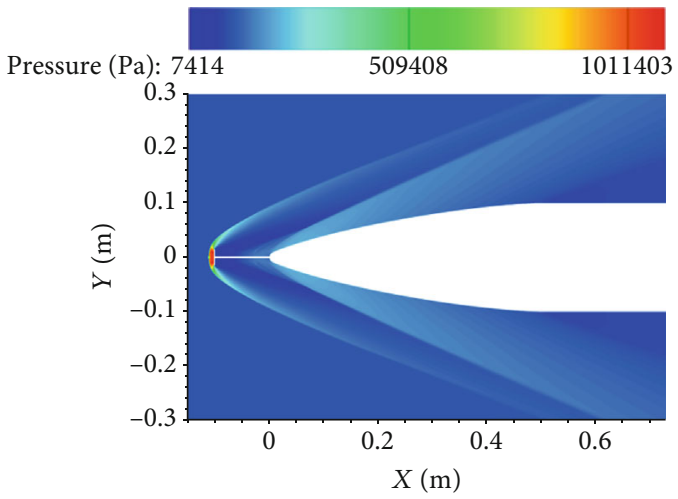

(f)

Figure 12: Continued. 


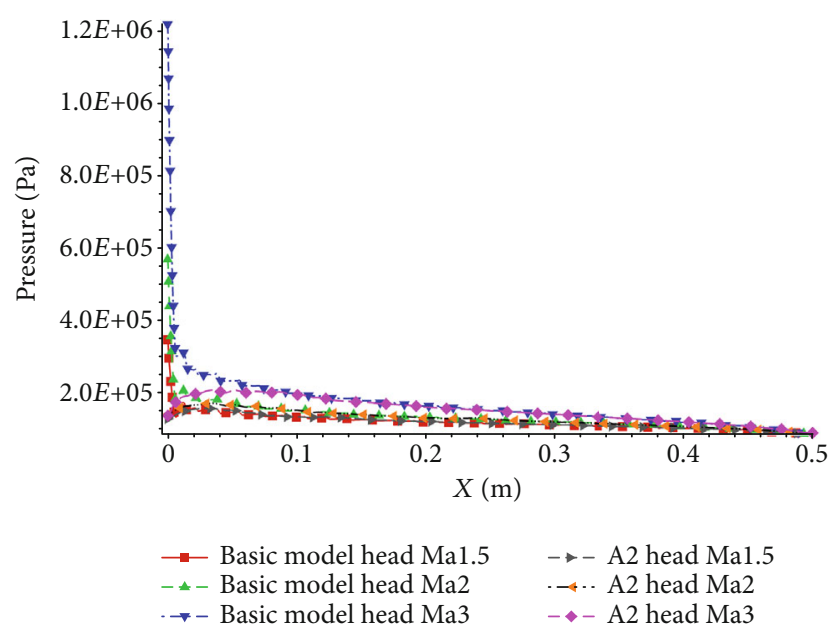

(g)

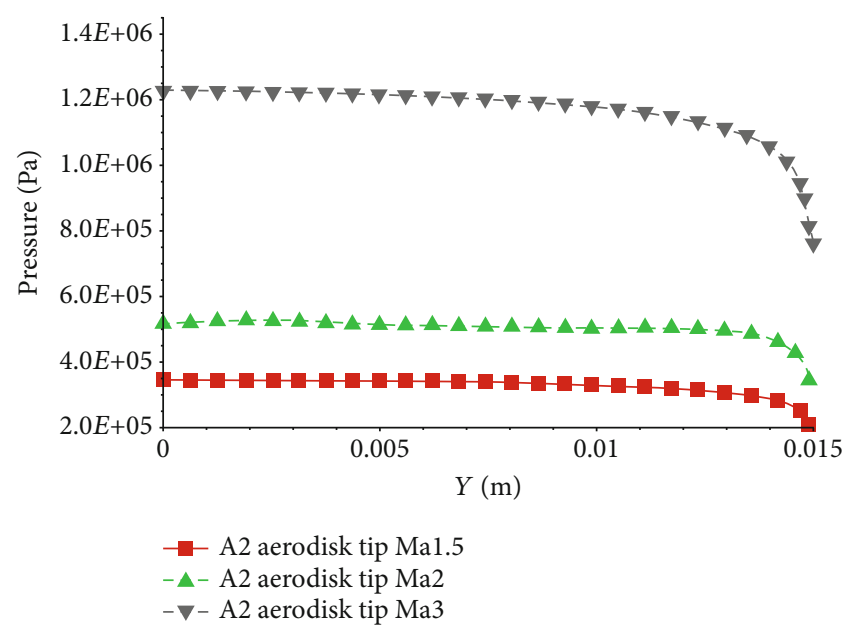

(h)

Figure 12: The flowfield feature of the A2 and basic model at three Mach numbers. (a) Pressure contour of the basic model at Mach number 1.5. (b) Pressure contour of the basic model at Mach number 2. (c) Pressure contour of the basic model at Mach number 3. (d) Pressure contour of A2 at Mach number 1.5. (e) Pressure contour of A2 at Mach number 2. (f) Pressure contour of A2 at Mach number 3. (g) Pressure curves of A2 head and basic model at three Mach numbers. (h) Pressure curves of A2 aerodisk tip at three Mach numbers.

When the supersonic flow passes through the aerodisk, the supersonic flow is impeded by the aerodisk, and the bow shock wave is created in front of the aerodisk. The speed of the flow decreases, the kinetic energy is converted to the internal energy, and the pressure and temperature behind the bow shock wave increase. When the flow contacts with the main body, the flow will be compress again, and the reattachment shock wave is created. Compared with the shock wave created by the vehicle body without aerospike, the intensity of reattachment shock wave is dropped. The fundament idea of the aerospike and aerodisk is to replace the shock wave created by the vehicle body. The flow behind the reattachment shock wave will expand because of the flow is extruded by the vehicle body wall, and the value of the pressure decreases in the expansion zone. Recirculation zone is formed behind the erodisk and the front of the head of the aircraft, and it can be seen that the pressure curve fluctuates in the two places. It is the recirculation zone generated that effects the pressure curve.

3.4. Influence of Incoming Mach Number. Combine with Figures 8 and 10, it can be seen that the drag reduction effect of the same aerospike at different Mach numbers is completely different. It shows that the same aerospike has different linfluences on the flowfield of the aircraft at different Mach numbers. Figure 12 shows the flowfield features of A2 and the basic model at three Mach numbers.

According to Figures 12(a)-12(c), it shows that the shock angle in front of the basic model decreases with the increase of the incoming Mach number, and the head pressure of the aircraft increases of the incoming Mach number. By Figures 12(d)-12(f), with the increase of the incoming Mach number, the shock angles of the bow shock wave generated at the front of the aerodisk, and the reattachment shock wave at the head of the aircraft also decreases gradually. For the same aerospike, the pressure improvement effect on the aircraft on the aircraft head is basically the same at different incoming
Mach numbers. As shown in Figure 12(g), A2 has the same change in the pressure on the aircraft at three different Mach numbers. The pressure distribution curve at the A2 aerodisk tip is the same, but the pressure value is different under different incoming Mach numbers. At Mach number 3, the pressure value of the aerodisk tip is the largest. Therefore, under different Mach numbers, the same aerospike has similar improvement effect on the head pressure of the aircraft, but the drag generated by the aerodisk tip increases with the increase of the incoming Mach number. The drag reduction effect of the same aerospike becomes worse with the increase of the incoming Mach number.

\section{Conclusion}

The drag of the vehicles at the supersonic flow can be decrease by some methods, and the aerospike is a useful method to reduce the shock wave drag. The mechanism of drag reduction by the aerospike is given by the numerical simulation results. With the aerodisk installing in front of the aerospike, the reattachment shock wave on the vehicle body is weaker than the shock wave on the vehicle without aerospike. The recirculation zone covers a part of the vehicle body, and it is helpful to reduce the drag.

The drag reduction effect influence of the parameters of the aerodisk radius and the aerospike length on the Carman Curve body is discussed, the aerodisk radius within a certain range is helpful for the pressure drag decrease on the Carman Curve body, but it will increase the pressure drag on the aerodisk, and the aerodisk radius has a balance point that have a best drag reduction effect. And the increase of the aerospike length is not useful for the drag reduction. Under different Mach numbers, the same aerospike has similar improvement effect on the head pressure of the aircraft, but the drag generated by the aerodisk tip increases with the increase of the 
incoming Mach number. The drag reduction effect of the same aerospike becomes worse with the increase of the incoming Mach number.

The Carman curve body has the good pressure distribution and aerodynamic characteristic, and the pressure change caused by the aerospike and aerodisk is not obvious. The maximum drag reduction rate of the Carman curve bodies with these models which calculated in this paper is $11.25 \%$. Therefore, when the aerospike and aerodisk used to the different vehicle body, it is necessary to study the optimum size of aerospike and aerodisk.

\section{Data Availability}

The data used to support the findings of this study are available from the corresponding author upon request.

\section{Conflicts of Interest}

The authors declare that there is no conflict of interest regarding the publication of theis paper.

\section{Acknowledgments}

This research was sponsored by the Research Project of National University of Defense Technology (Project No. ZK19-11).

\section{References}

[1] F. Xue, The Characteristice Research of Lift Enhancement and Drag Reduction on aircraft, Nanjing University of Aeronautics and Astronautics, Nanjing, 2013.

[2] M. Y. M. Ahmed and N. Qin, "Recent advances in the aerothermodynamics of spiked hypersonic vehicles," Progress in Aerospace Sciences, vol. 47, no. 6, pp. 425-449, 2011.

[3] X. Sun, W. Huang, M. Ou, R. Zhang, and S. Li, "A survey on numerical simulations of drag and heat reduction mechanism in supersonic/hypersonic flows," Chinese Journal of Aeronautics, vol. 32, no. 4, pp. 771-784, 2019.

[4] V. Menezes, S. Saravanan, G. Jagadeesh, and K. P. J. Reddy, "Experimental investigations of hypersonic flow over highly blunted cones with aerospikes," AIAA Journal, vol. 41, no. 10, pp. 1955-1966, 2003.

[5] M. Y. M. Ahmed and N. Qin, "Forebody shock control devices for drag and aero-heating reduction: a comprehensive survey with a practical perspective," Progress in Aerospace Sciences, vol. 112, p. $100585,2020$.

[6] S. R. Alexander, Results of tests to determine the effect of a conical windshield on the drag of a bluff body at supersonic speeds, National Aeronautics and Space Administration Hampton Va Langley Research Center, 1947.

[7] W. E. Moeckel, Flow separation ahead of a blunt axially symmetric body at Mach numbers 1.76 to 2.10, National Advisory Committee for Aeronautics, 1951.

[8] W. A. Mair, "LXVIII. Experiments on separation of boundary layers on probes in front of blunt-nosed bodies in a supersonic air stream," The London, Edinburgh, and Dublin Philosophical Magazine and Journal of Science, vol. 43, no. 342, pp. 695-716, 1952.
[9] J. J. Jones, Experimental drag coefficients of round noses with conical wind-shields at Mach Number 2.72, NACA RM, 1955, L55E10.

[10] D. Beastall and J. Turner, The effect of a spike protruding in front of a bluff: body at supersonic speeds, vol. 3007, Aeronautical Research Council, 1957.

[11] S. M. Bogdonoff and I. E. Vas, "Preliminary investigations of spiked bodies at hypersonic speeds," Journal of the Aerospace Sciences, vol. 26, no. 2, pp. 65-74, 1959.

[12] D. H. Crawford, Investigation of the flow over a spiked-nose hemisphere-cylinder at a Mach number of 6.8, National Aeronautics and Space Administration, 1959.

[13] C. J. Wood, "Hypersonic flow over spiked cones," Journal of Fluid Mechanics, vol. 12, no. 4, pp. 614-624, 1962.

[14] M. Holden, "Experimental studies of separated flows at hypersonic speeds. I - separated flows over axisymmetric spiked bodies," AIAA Journal, vol. 4, no. 4, pp. 591-599, 1966.

[15] V. S. Khlebnikov, "Distribution of heat flux on the surface of a sphere with a forward separation zone," Fluid Dynamics, vol. 21, no. 4, pp. 654-658, 1986.

[16] N. Motoyama, K. Mihara, and R. Miyajima, "Thermal protection and drag reduction with use of spike in hypersonic flow," in 10th AIAA/NAL-NASDA-ISAS International Space Planes and Hypersonic Systems and Technologies Conference, vol. 2001, Kyoto, Japan, 2001.

[17] S. S. Milicev and M. D. Pavlovic, "Influence of spike shape at supersonic flow past blunt-nosed bodies: experimental study," AIAA Journal, vol. 40, no. 5, pp. 1018-1020, 2002.

[18] V. N. Myshenkov, "Numerical investigation of separated flow in front of a spiked cylinder," Fluid Dynamics, vol. 16, no. 6, pp. 938-942, 1981.

[19] V. M. Paskonov and N. A. Cheraneva, "Numerical investigation of laminar separation in the case of supersonic flow of viscous gas past spiked bodies," Fluid Dynamics, vol. 19, no. 2, pp. 281-285, 1984.

[20] V. N. Karlovskii and V. I. Sakharov, "Numerical investigation of supersonic flow past blunt bodies with protruding spikes," Fluid Dynamics, vol. 21, no. 3, pp. 437-445, 1986.

[21] A. G. Mikhail, "Spike-nosed projectiles - computations and dual flow modes in supersonic flight," Journal of Spacecraft and Rockets, vol. 28, no. 4, pp. 418-424, 1991.

[22] J. T. White, "Application of Navier-Stokes flowfield analysis to the aerothermodynamic design of an aerospike-configured missile," in Aerospace Design Conference, Irvine, CA, U. S. A, 1993.

[23] K. H. Hur, S. T. Kirn, and D. H. Lee, "Numerical analysis on supersonic, viscous flowfield around a spike-nosed projectile with fins," in 21st Atmospheric Flight Mechanics Conference, San Diego, CA, U.S.A, 1996.

[24] A. G. Mikhail, "Spike-nosed projectiles with vortex rings: steady and nonsteady flow simulations," Journal of Spacecraft and Rockets, vol. 33, no. 1, pp. 8-14, 1996.

[25] M. Yamauchi, K. Fujii, and F. Higashino, "Numerical investigation of supersonic flows around a spiked blunt body," Journal of Spacecraft and Rockets, vol. 32, no. 1, pp. 32-42, 1995.

[26] R. C. Mehta, "Numerical heat transfer study over spiked blunt bodies at Mach 6.8," Journal of Spacecraft and Rockets, vol. 37, no. 5, pp. 700-703, 2000.

[27] M. Gauer and A. Paull, "Numerical investigation of a spiked blunt nose cone at hypersonic speeds," Journal of Spacecraft and Rockets, vol. 45, no. 3, pp. 459-471, 2008. 
[28] P. Gnemmi, J. Srulijes, K. Roussel, and K. Runne, "Flowfield around spike-tipped bodies for high attack angles at Mach 4.5," Journal of Spacecraft and Rockets, vol. 40, no. 5, pp. 622-631, 2003.

[29] Y. Xue, L. Wang, and S. Fu, "Drag reduction and aerodynamic shape optimization for spike-tipped supersonic blunt nose," Journal of Spacecraft and Rockets, vol. 55, no. 3, pp. 552-560, 2018.

[30] J. D. Anderson, Computational fluid dynamics, China Machine Press, Beijing, 2007.

[31] F. R. Mentet, "Two-equation eddy-viscosity turbulence models for engineering applications," AIAA Journal, vol. 32, no. 8, pp. 1598-1605, 1994.

[32] J. Wei, Y. Yunjun, and C. Hewu, "Investigations on aerodynamics of the spike-tipped hypersonic vehicles," Journal of Experiments in Fluid Mechanics, vol. 25, no. 6, pp. 28-33, 2011. 